\title{
O PENSAR E O FAZER DOCENTE NO CLUBE DE CIÊNCIAS DA UFPA: REFLEXÕES SOBRE A PRÁTICA
}

\author{
Dércio Pena Duarte ${ }^{1}$ \\ Andrela Garibaldi Loureiro Parente ${ }^{2}$
}

\section{RESUMO}

Este artigo trata de discussões e reflexões a partir da prática docente de um grupo de professores-estagiários do CCIUFPA. A partir do relato das atividades desenvolvidas, investigamos que elementos / relações / discussões envolveram o pensar e o fazer do grupo, procurando compreender de que modo as atividades foram realizadas e discutindo elementos que surgiram no decorrer do trabalho. Recorremos ao planejamento das atividades, aos trabalhos desenvolvidos pelos alunos e a entrevistas com os professores. Buscamos relações entre as idéias dos professores sobre as atividades e sua execução, estabelecendose como ponto principal de comparação visões sobre a atividade científica, que poderiam determinar a forma como os conhecimentos dos alunos seriam tratados pelos professores e como as atividades poderiam modificar visões distorcidas. Concluímos que o pensar e o fazer devem estar associados na ação docente

Palavras-chave: formação docente; ensino de ciências; espaço não formal de ensino.

\section{ABSTRACT}

This article discusses and reflects on the teaching practical of a group of teachers on formation of CCIUFPA. In the telling of developed activities, we investigate that elements /relations/discussions had involved thinking and making of this group, looking for to understand of that way the activities had been realized and discussing elements that had appeared in the elapse on the work. We appeal to the planning of the activities, to the works developed for the pupils and to interviews with the teachers. We search relations between the ideas of the teachers on the activities and its execution, establishing as main point of comparison conceptions about the scientific activity, which could determine the form as the knowledge of the pupils would be treated by the teachers and as the activities could modify distorted conceptions. We concluded that thinking and making they must be associates in the teaching action.

Keywords: teacher formation; science teaching; non-formal teaching space.

\section{INTRODUÇÃO}

Envolver os professores em pesquisa tem sido apontado como um dos caminhos válidos para melhorar a educação brasileira. Conhecimento sobre a complexidade que envolve o processo de ensinoaprendizagem, inter-relação teoria e prática, crescimento intelectual e profissional podem ser desenvolvidos e mediados por práticas de pesquisa. Assim, pesquisar sobre a própria prática pode possibilitar mudanças significativas na atuação do professor, seja na formação inicial ou continuada.

Este artigo trata de discussões e reflexões a partir da prática docente de um grupo de professoresestagiários, do Clube de Ciências da UFPA CCIUFPA, durante o ano de 2005, em que se trabalhou com uma turma do ensino médio. $\mathrm{O}$ CCIUFPA, situado no Núcleo Pedagógico de Apoio ao Desenvolvimento Científico NPADC/UFPA, é um espaço que desenvolve a prática de ensino antecipada e compartilhada (GONÇALVES, 2000). Incentiva e orienta a formação do professor pela pesquisa, compartilhando com a idéia de professorpesquisador, como defendida por Maldaner (1999).

Por se tratar de um espaço não-formal de ensino de Ciências, o Clube de Ciências da UFPA propicia um ambiente de aprendizado diferente. Por meio do desenvolvimento de atividades variadas com estudantes de ensino fundamental e médio, os alunos têm oportunidade de adquirir uma bagagem

${ }^{1}$ Mestre em Educação em Ciências e Matemáticas pela Universidade Federal do Pará, Professor da Universidade Federal do Oeste do Pará - UFOPA.

${ }^{2}$ Mestre em Educação em Ciências e Matemática pela Universidade Federal do Pará, Professor da Universidade Federal do Pará. 
cognitiva de assuntos relacionados à ciência, podendo eles mesmos desenvolver projetos de pesquisa, articulando teoria e prática no processo de aprendizagem.

Com a idéia de incentivar/possibilitar uma visão de ciência diferente do que é comumente disseminado, e, em função de perceber que a produção do conhecimento precisa ser vista de outra maneira, o grupo de professores-estagiários organizou um conjunto de atividades que buscou atingir estes objetivos. Essas atividades foram desenvolvidas no ano letivo de 2005 e contaram com uma equipe interdisciplinar de professoresestagiários do Clube de Ciências da UFPA.

Vários são os autores que se propõem a estudar o trabalho dos cientistas como algo distinto das idéias recorrentes sobre a atividade científica, que podemos caracterizar como impessoal, neutra, universal e em busca da verdade. Esta visão, transmitida por grande parte dos livros didáticos, é a que se apresenta como correta para os estudantes. Vários dos autores que criticam tal visão acreditam no uso da História da Ciência no ensino de Ciências como via de mudança. Uma análise de alguns casos ao longo da história das descobertas científicas mostra que há muito mais em jogo do que simplesmente a busca pela verdade por alguns poucos gênios excepcionais, envolvendo antes de tudo o caráter ambíguo e socialmente construído das ciências surgidas no curso do tempo. São construções humanas, portanto, suscetíveis a erros, interesses, paixões, disputas, intrigas e consensos, o que é muito diferente daquela visão de ciência neutra, objetiva e infalível que se convencionou trabalhar no ensino tradicional, por meio da desconexão entre as várias disciplinas, menosprezo às formas de conhecimento construídas pelos estudantes em sua vida e a ênfase à transmissão de conteúdos pelo professor sem qualquer base crítica.

Silenciosamente, o conteúdo transmitido é acompanhado de um ideário que o próprio professor por vezes não tem consciência, que, de um modo geral, são idéias que remetem à ciência como maneira única de pensar o mundo, neutra, ahistórica e infalível. Gil Pérez et al. (2001) apontam sete concepções deformadas sobre o trabalho científico que são transmitidas pelos professores. Em vista dessas concepções com que os professores representam a ciência para os estudantes, perde-se a noção do que constitui de fato o trabalho científico. procuramos responder à questão: A partir do relato das atividades desenvolvidas em 2005, que elementos/relações/discussões envolveram o pensar e o fazer dos professores-estagiários que compuseram a turma?

Para responder a esta questão, buscamos, ao longo do trabalho, discutir as visões dos alunos e professores da turma Ensino Médio B sobre a atividade científica e sobre o desenvolvimento das atividades do ano letivo de 2005, além de identificar, nos discursos de ambos os lados, elementos que denotem a influência ou não das atividades do ano nas visões sobre ciência que alunos e professores demonstraram.

Optamos pela pesquisa narrativa no desenvolvimento do trabalho por considerá-la uma metodologia de investigação que atende aos propósitos apresentados. Trata-se de uma re-análise das experiências vividas pelos indivíduos participantes, incluindo-se aí o próprio pesquisador. Cunha (1997) destaca a importância dos significados atribuídos aos fenômenos pelo sujeito da pesquisa, devendo este estar disposto a analisar criticamente a si próprio, a separar olhares enviezadamente afetivos presentes na caminhada, a por em dúvida crenças e preconceitos, enfim, a des-construir seu processo histórico para melhor poder compreendêlo.

$\mathrm{Na}$ condição de sujeitos diretamente envolvidos no processo de pesquisa, tanto quanto objeto, portanto suscetível a re-interpretar as narrativas, percebemos na pesquisa narrativa uma possibilidade de auto-análise e de análise das falas dos demais professores e dos alunos, constituindo assim um processo coletivo de mútua explicação em que a vivência do investigador se imbrica na do investigado (idem).

Partindo do princípio de que dentro de uma pesquisa nessa vertente a narrativa é tanto o fenômeno que se investiga como o método da investigação (GONÇALVES, 2000), apresentamos, na forma de narração, algumas reflexões sobre as várias interpretações do desenvolvimento das atividades, que permitirão compreender de que modo as atividades foram realizadas, discutindo elementos que surgiram no decorrer do trabalho.

Diante das considerações apresentadas, 


\section{O CLUBE DE CIÊNCIAS DA UFPA COMO ESPAÇO NÃO-FORMAL DE ENSINO DE CIÊNCIAS}

Define-se educação não-formal como qualquer tentativa educacional organizada $e$ sistemática que, normalmente, se realiza fora dos quadros do sistema formal de ensino (BIANCONI e CARUSO, 2005). Diferencia-se da educação informal, que se adquire na convivência cotidiana na família, em clubes, associações de moradores, centros religiosos e outros espaços, de forma assistemática. Também se diferencia da educação formal por não se realizar no ambiente escolar. Como exemplos de espaços não-formais de educação, temos museus, parques zoobotânicos, planetários e clubes de ciências. As atividades da educação não-formal são geralmente desenvolvidas de modo a atingir um objetivo específico (VIEIRA et al., 2005), podendo favorecer a aquisição de bagagem cognitiva pelo aluno em auxílio ao processo escolar (idem). Dentro destes espaços, é possível o desenvolvimento de determinados conteúdos que podem ou não seguir a organização curricular do ensino formal. O Clube de Ciências da UFPA (CCIUFPA), exemplo de espaço não-formal em Belém, corresponde à definição mencionada e possui características próprias que a diferenciam da educação formal de Ciências. No ano de 2005, neste espaço não-formal de ensino de Ciências, foram desenvolvidas as atividades que buscamos descrever/discutir neste trabalho.

A turma de ensino médio em que se realizou a pesquisa (Ensino Médio B) foi formada por seis professores-estagiários de cinco cursos da UFPA (Biologia, Filosofia, Física, Matemática e Química), com diferentes tempos de estágio no Clube de Ciências. A equipe se formou por compatibilidade de horários e interesse comum pela proposta de trabalho que foi definida durante a realização da Semana de Capacitação de professores-estagiários do CCIUFPA, realizada nos meses de janeiro e fevereiro de 2005. Passaremos, a seguir, a apresentar algumas informações sobre cada professor do grupo.

Armando ${ }^{3}$ iniciou seu estágio no Clube em 2004, ano em que cursava Pedagogia. Em 2005, mudou-se para o curso de Filosofia através da Mobilidade Acadêmica ("vestibulinho"). Nesse mesmo ano, teve sua primeira experiência com uma turma de Ensino Médio, sendo um dos primeiros, juntamente comigo, a se interessar pelo tema
História da Ciência e a integrar o grupo de professores.

Danilo ingressou no Clube, em 2005, tendo ingressado no curso de Licenciatura em Matemática em 2002. Possui experiência em algumas escolas particulares da Grande Belém.

Maurício ingressou no Clube, em 2003, tendo se afastado no segundo semestre de 2004 e retornado em 2005. É concluinte de Licenciatura em Física, curso iniciado em 2001. Trabalha como professor de cursinhos pré-vestibulares da Grande Belém.

Rodrigo também iniciou seu estágio no Clube, em 2003, tendo ingressado na Licenciatura em Física, em 2002. Tem experiência em cursinhos pré-vestibulares e como monitor em um programa de inclusão digital.

Walter participa do Clube desde 2004, tendo, em 2005, sua primeira experiência no Ensino Médio. Encontrava-se no quinto semestre do curso de Bacharelado em Química, no qual ingressou, em 2003, na época da realização da pesquisa; tem experiência docente com aulas particulares.

Dércio integrou o grupo de professores de 2005 , tendo ingressado no estágio, em 2003. Entrou no curso de Licenciatura em Biologia, em 2002, e, desde agosto de 2004, foi bolsista da Pró-Reitoria de Extensão (PROEX) pelo Clube de Ciências.

Na turma de Ensino Médio B, inscreveram-se 35 sócios-mirins. Apenas 19 compareceram no primeiro dia de atividades no Clube. Neste dia, foi aplicado o questionário sócio-cultural. Este questionário e as fichas de inscrição forneceram os subsídios para as informações que compõem o perfil dos alunos.

Para os propósitos da pesquisa, selecionamos diferentes instrumentos que nos ajudarão a discutir/refletir sobre o pensar e o fazer no Clube de Ciências da UFPA. inicial)

Avaliação de concepções prévias (sondagem

Esta sondagem foi realizada ainda no primeiro dia de aula e consistiu em um questionário com duas perguntas de resposta livre, que versavam sobre as concepções dos alunos em relação à Ciência e à atividade do cientista. Foi distribuído após uma breve exposição da proposta de trabalho com a turma

Atividade sobre Razão Áurea

O tema da aula do dia 9 de abril de 2005 foi 
Razão Áurea. A aula iniciou com o eixo temático Corpo, proposto pelo grupo de professores. Foi elaborado um material escrito com algumas informações históricas e matemáticas sobre a Divina Proporção. Este material continha no final uma tabela na qual cada aluno deveria anotar, após medições, sua altura, a distância do umbigo ao chão e a razão entre as medidas anteriores, para estimarem o quanto aquela se aproxima da Razão Áurea ou Número de Ouro.

\section{Pesquisa aberta sobre Padrões de Beleza}

Como forma de ambientar os alunos aos projetos de iniciação científica que seriam realizados ao longo do ano, adotamos o procedimento de, a cada semana, elegermos uma dupla de alunos para realizarem uma pesquisa sobre o tema da aula seguinte, na qual seriam apresentados os resultados. Como primeira pesquisa, delegamos a uma dupla a função de entrevistarem no mínimo dez pessoas sobre padrões de beleza, a partir da pergunta-chave Para você, o que é o belo? Os resultados apresentados na segunda aula tornaram-se base para o assunto do dia.

\section{Construção de hipóteses}

Esta atividade que durou duas aulas foi particularmente importante, pois envolveu a habilidade de levantamento de hipóteses pelos alunos. Diante de uma experiência envolvendo um recipiente cheio de água, uma vela acesa dentro do recipiente e um copo, os alunos deveriam responder à questão: se colocarmos o copo sobre a vela acesa, $o$ que acontece com a chama da vela e com a água do recipiente? Os alunos deveriam levantar hipóteses antes da realização do experimento e buscar explicações para o resultado obtido, o que seria feito oralmente e por meio de um relatório a ser entregue no segundo dia da atividade. Esse trabalho escrito foi entregue por apenas uma aluna.

Texto sobre elementos para uma investigação

Este texto, adaptado de Hennig (1986), foi apresentado como parte do eixo temático Elaboração de um trabalho científico, em que pretendíamos discutir com os alunos elementos de um trabalho científico a partir da experiência relatada por Lazzaro Spalanzani com morcegos, que levou séculos mais tarde à invenção do sonar. Os alunos responderam a uma série de questões referentes às hipóteses levantadas pelo pesquisador, os objetivos da pesquisa e outras relacionadas com os elementos de um trabalho científico.

\section{Sondagem final}

No dia da Feira de Ciências, que marcou o final das atividades do Clube de Ciências, em 2005, foi distribuído para os alunos um questionário sobre as atividades desenvolvidas na turma. Dos cinco questionários entregues, três foram respondidos e devolvidos aos professores-estagiários; destes, serão analisadas algumas respostas na tentativa de discutir aspectos da prática, de acordo com as questões propostas.

\section{Entrevistas com os professores}

Os professores-estagiários da turma Ensino Médio B foram entrevistados cinco meses após o encerramento das atividades de 2005 no CCIUFPA. Foram realizadas entrevistas individuais semiestruturadas com base em um modelo de entrevista com questões relativas ao trabalho no Clube de Ciências, à influência deste trabalho em sua formação profissional e às concepções que possuem sobre a atividade científica em comparação com a que possuíam antes de entrar na Universidade. Estas entrevistas foram registradas com o auxílio de um gravador e os trechos considerados mais relevantes para a análise foram transcritos.

\section{A EXPERIÊNCIA DOCENTE NO ENSINO DE CIÊNCIAS DO CCIUFPA}

Para os propósitos do trabalho a ser desenvolvido, em 2005, foi interessante conhecer que concepções sobre a atividade científica os alunos apresentavam inicialmente. Para esta sondagem inicial, foram feitas duas perguntas na forma de questionário de livre resposta, Como você imagina a Ciência? O que faz um cientista? Embora sejam perguntas diferentes, as respostas estão diretamente relacionadas, o que nos faz preferir analisá-las em conjunto. As respostas seguintes representam algumas das idéias que os alunos apresentaram no início das atividades, com suas possíveis interpretações entre parênteses.

Um meio [em] que se estuda a vida e os demais assuntos relacionados à existência dos seres na terra (ciência unicamente como estudo da vida).

Seu trabalho é criar e descobrir para a melhoria da vida humana. Tudo parte de uma necessidade que os seres humanos possuem e eles, os cientistas, procuram a solução (Ciência para a melhoria da vida humana). 
Um cientista tenta descobrir coisas novas (Ciência composta por descobertas, em detrimento da construção histórica da Ciência).

(...) Alguns cientistas fazem da Ciência um instrumento para causar destruição, outros salvam (...) vidas (caráter ambíguo da Ciência).

As diferentes respostas mostram algumas das visões possíveis sobre ciência que os alunos trouxeram naquele primeiro dia de aula. Essas visões podem ser o reflexo tanto do que é transmitido pela escola quanto da visão parcializada dos meios de comunicação, em especial da mídia televisiva (KOSMINSKY E GIORDAN, 2002). Identificar estas visões iniciais sobre Ciência e a atividade científica nos permitiu enxergar a variedade de concepções que os alunos podem trazer sobre a Ciência. Estas várias concepções também foram identificadas pelos professores nas entrevistas. Armando e Rodrigo, por exemplo, emitiram as seguintes respostas quando interrogados acerca de uma possível mudança de idéia sobre a Ciência em relação ao que pensavam antes do ingresso na universidade:

Via a Ciência como algo realmente fantástico e até certo ponto feito por gênios, devido às publicações da mídia de massa que expõem o cientista como gênio (...) muitas vezes confundia a Ciência com seu produto, a tecnologia (...). (ARMANDO, 23, Filosofia)

Quando a gente é aluno de ensino médio, a gente pensa que cientista é o cara que tá no laboratório de jaleco... faz um estereótipo de cientista... cabelo arrepiado... e hoje em dia a gente vê que não é assim (...). (RODRIGO, 24, Física)

Armando e Rodrigo, por exemplo, trazem em seus depoimentos visões estereotipadas sobre a figura do cientista, que refletem como vêem a própria Ciência. Estas concepções distorcidas sobre a atividade científica podem persistir nos professores, quando se preocupam unicamente em transmitir conteúdos da Ciência sem analisá-los criticamente, apesar da formação científica da academia (GIL PÉREZ et al., 2001). De maneira implícita ou bem clara, o fazer científico é tratado nas salas de aula como uma atividade neutra, eminentemente empírica, rigorosamente metódica e fruto de idéias geniais de indivíduos isolados, dentre outras características que não correspondem à realidade das universidades e centros de pesquisa (idem).

Nas aulas seguintes, foram desenvolvidas diversas atividades. Algumas delas foram selecionadas e indicadas anteriormente para análise do pensar e do fazer dos professores-estagiários da turma.

A Razão Áurea, segunda atividade, ( ou phi) foi tema da aula seguinte, na qual foi trabalhada uma atividade prática que consistiu na medição das alturas dos alunos pelas distâncias de seus umbigos ao chão, cuja razão entre as medidas resultaria aproximadamente no número 1,618, que corresponde à Razão Áurea. Este número adquiriu uma conotação mística desde a Antiguidade, onde se imaginava que era possível encontrar um número que regesse a natureza. Como esta proporção pode ser encontrada em vários aspectos naturais, desde o padrão da espiral da concha de algumas espécies de moluscos marinhos até a razão entre várias medidas do corpo humano, muitos artistas a utilizaram para imprimir apuro estético em suas obras. Algumas relações matemáticas em figuras geométricas também se configuram em relações áureas (BIEMBENGUT e HEIN, 2003). Os valores obtidos se aproximavam da Razão Áurea, alguns mais, outros menos. Apenas em um aluno houve coincidência entre a razão de suas medidas e o Número de Ouro. Porém, ele não foi considerado como um "padrão de beleza" pelos colegas, o que os levou à conclusão de que não é possível determinar a beleza de maneira matemática. Tratou-se de uma aula interessante, na qual pudemos exercitar a interdisciplinaridade que é uma das metas do Clube de Ciências da UFPA.

Com a finalidade de introduzirmos os alunos no desenvolvimento de projetos de iniciação científica que seriam desenvolvidos na Feira de Ciências interna do CCIUFPA, foi proposto a dois deles uma pesquisa, que consideramos com terceira atividade. Eles deveriam realizar entrevistas com no mínimo 10 pessoas de seu convívio, baseando-se na questão: Para você, o que é o belo?As respostas deveriam ser agrupadas e os resultados obtidos apresentados na aula seguinte, como forma de iniciar o assunto padrões de beleza. A pesquisa, porém, foi além do que havia sido solicitado.

Os dois estudantes haviam entrevistado 10 homens e 10 mulheres para responder à pergunta que foi proposta e a outras perguntas complementares, como: Que exemplo você pode dar de homem/mulher bonito (a)? O que você acha da maquiagem? e $O$ que você acha de homens musculosos? As duas primeiras perguntas foram dirigidas aos homens e as duas últimas às mulheres. 
Os estudantes, ao apresentarem o trabalho, interagiram bastante com a turma, repetindo as perguntas das entrevistas aos colegas e aos professores. Para ilustrar o resultado da pesquisa, eles elaboraram um cartaz com recortes de vários exemplos de beleza mencionados pelos entrevistados. Alguns viam beleza em pessoas bonitas, outros viam beleza na religião, outros viam beleza em paisagens, enquanto outros viam beleza em bens materiais.

A abordagem deste eixo temático agradou aos professores e à maioria dos alunos, pelo que pudemos perceber com uma avaliação posterior das atividades do primeiro semestre. Apenas um manifestou seu desagrado em relação às atividades. Este aluno, que participava do Clube desde 2004, já havia desenvolvido um projeto de iniciação científica premiado, estando talvez entediado de trabalhar algo onde não "via ciência". Como incentivar o interesse daquele aluno por meio daquela atividade? Naquele momento, não houve resposta por parte dos professores-estagiários, levando-os a não dar maior atenção ao caso.

A quarta atividade, que envolveu a realização de um experimento, é particularmente relevante para a questão proposta neste artigo. Com um jarro de vidro, duas velas, uma vasilha rasa de vidro, uma caixa de fósforos e água, seria possível incentivar os alunos a levantarem hipóteses de previsão do experimento e hipóteses de explicação, depois de realizado. $\mathrm{O}$ experimento consistiu em cobrir o fundo da vasilha com água e nela colocar uma vela acesa. Sobre a vela acesa, o jarro de vidro deveria ser emborcado. A questão inicial foi especular o que acontece com a chama da vela e com o nível da água da vasilha. As alunas presentes na aula foram incentivadas a emitirem suas hipóteses sobre esta questão. Uma das hipóteses iniciais considerava que a vela permaneceria acesa por influência da água do recipiente, enquanto as demais hipóteses consideravam que a vela iria se apagar. Uma outra hipótese considerou que o nível da água dentro do jarro subiria, enquanto as demais consideravam que o nível permaneceria o mesmo. $\mathrm{O}$ experimento foi realizado por elas e resultou na extinção da chama e na subida do nível da água dentro do jarro. A partir daí, as alunas foram incentivadas a construir hipóteses para explicar o porquê daquele resultado. Essas hipóteses foram registradas de forma escrita no primeiro dos dois dias em que se realizou esta atividade.

A nosso ver, esse foi o momento mais interessante da aula, pois elas passaram a emitir suas explicações sobre o fenômeno. Uma delas sugeriu que havia oxigênio dentro do jarro alimentando a chama da vela, que foi transformado em energia pelo calor da chama e por isso fez com que se apagasse. Outra aluna propôs que o nível da água dentro do jarro impediria a vela de ficar acesa. A outra aluna introduziu a idéia de uma pressão no interior do jarro que aumentaria com a subida do nível da água, sendo essa subida provocada pelo acúmulo de calor no jarro. Os professores-estagiários faziam uma ou outra intervenção no sentido de estimular a inclusão de novos fatores nas hipóteses. Uma destas intervenções foi insinuar a influência do lado externo do jarro no resultado do experimento. As hipóteses, a partir daí, passaram a considerar a existência de uma pressão de fora para dentro, que surgia pela "falta de ar" dentro do jarro. Uma hipótese considerou que a chama "puxa" o ar para dentro do jarro, mas a água forma uma barreira e acaba sendo "puxada".

Foi permitido às alunas repetirem o experimento quantas vezes considerassem necessárias, alterando alguns fatores, como o tamanho da vela utilizada, para comprovação ou descarte das hipóteses. Algumas ainda se mantiveram, como a existência de uma pressão interna no jarro que "puxa" água para dentro, que poderia ser criada tanto pela ausência do ar quanto pelo excesso de calor no interior do jarro. Uma nova hipótese surgiu sobre a transformação de substâncias devido à influência do calor, que no experimento era representada pela transformação do oxigênio em outra substância que não tinha a propriedade de alimentar a chama da vela. Como tempo estava se esgotando, foi solicitado que as estudantes fizessem um relatório sobre o experimento, incluindo suas hipóteses antes do experimento e suas explicações para o que havia ocorrido. Apenas uma delas preparou o relatório, no qual constam suas hipóteses. As hipóteses levantadas podem ser resumidas da seguinte forma: uma das alunas acreditava no acúmulo de calor dentro do jarro como causador de uma pressão interna que puxou a água; outra acreditava que a falta de oxigênio dentro do jarro induzia a entrada de ar no jarro, o que fazia a água subir; a outra aluna concordava com esta última opinião.

Essa atividade pode ser analisada sob a ótica de uma evolução científica diferente daquela tradicionalmente repassada pela mídia e pela educação acrítica. Algumas das hipóteses levantadas antes da realização da experiência foram derrubadas 
diante do fato, mas as hipóteses para a explicação do fenômeno se sustentaram em essência, mesmo com as intervenções dos professores. Esta forma de trabalhar com o experimento guarda semelhanças com o tratamento que Karl Popper (1902-1994) dá ao desenvolvimento científico, isto é, por meio do abandono de teorias refutadas e adoção de teorias até o momento capazes de explicar o fenômeno em questão. Com esta abordagem, seria possível, como orientam Calor e Santos (2004), mostrar que a construção científica não reflete somente um conjunto de sensações individuais, estando este conjunto atrelado à elaboração de hipóteses e teorias na busca de se explicar a realidade. Desta forma, os alunos poderiam desenvolver visões de mundo próprias sem perder a noção dos princípios científicos (idem).

No entanto, não foi o que aconteceu. As intervenções que foram emitidas não alteraram significativamente as hipóteses levantadas, mantendo-se ideias como a da influência de uma pressão interna na subida do nível da água no jarro. Comparamos esta insistência das estudantes em manter suas hipóteses com a evolução científica defendida por Imre Lakatos (1922-1974), em que uma teoria se mantém enquanto um corpo de teorias auxiliares puder anular as refutações ao núcleo duro da questão. As intervenções dos professoresestagiários e as repetições do experimento incluíram novos elementos nas hipóteses, em vez de as refutarem.

As ideias que os alunos têm sobre determinados fenômenos, chamadas atualmente de concepções alternativas (SILVEIRA, 1992), conflitam com as ideias que se pretende que sejam aprendidas, vindas da ciência. Autores como Zylbersztajn (1991) e Silveira (1991) propõem um tratamento destas concepções alternativas a exemplo das idéias de construção do conhecimento científico propostas por Thomas Kuhn (1922-1996) e Karl Popper, respectivamente. Retomamos aqui as falas dos professores-estagiários sobre o papel que atribuem como professores diante da confrontação entre diferentes idéias, neste caso, a respeito da própria atividade científica:

Eu não costumo chamar de professor, costumo chamar de orientador, porque professor pra mim é aquele cara que sabe tudo, e a gente sabe que ninguém sabe tudo, então costumo falar que o orientador é fundamental na vida do aluno porque (...) ele pega as idéias do aluno e tenta orientar esse aluno para seguir algum caminho que dá em geral para um resultado da ciência ou qualquer coisa assim, ou seja, o aluno sem o orientador ou professor pode ou não chegar naquele resultado, se ele chegar ele vai demorar um pouquinho, e com o professor ele chega ao mesmo resultado rapidamente (DANILO, 23, Matemática).

Danilo enxerga o aluno como alguém que precisa do professor/orientador para chegar de forma segura no resultado da ciência. $\mathrm{O}$ aluno parece não ser possuidor de idéias próprias, carecendo das idéias científicas para as quais o professor o direciona.

Tem uma coisa que o Paulo Freire coloca que é preciso ouvir o que eles [os estudantes] têm, qual é o mundo em que realmente eles vivem, então, de posse desse mundo que eles vivem, muitas das coisas são mitos, que eles já têm... muitas das coisas acabam sendo transmitidas de pai pra filho, parentes e coisas... senso comum, né?(...) A gente acaba contribuindo no sentido de resolver alguns desses problemas que eles têm: isso é verdade, não é, como é queé, então? (...) (MAURÍCIO, 26, Física).

Maurício acredita que as visões que os alunos trazem são mitos, originados do que se chama senso comum. Neste sentido, estas visões se tornam problemas a serem resolvidos pelo professor, que deve indicar o que é certo e verdadeiro, ou melhor, o que é científico.

Resgatando as idéias sobre a ciência que os alunos manifestaram no questionário de sondagem inicial, muitas visões não remetem ao que seja de fato a ciência. Porém, não acreditamos que romper com estas visões que os alunos possam trazer signifique aos professores impor suas próprias idéias. Ressaltamos novamente que estas também podem ser idéias distorcidas, afastando mais ainda o aluno da possibilidade de ver a Ciência criticamente.

Paradoxalmente, em vez de ser uma experiência enriquecedora, a multiplicidade de idéias se tornou um empecilho para o desenvolvimento da atividade. Isso porque tínhamos em mente trazer as alunas para a Ciência, mostrarlhes as explicações científicas dos fenômenos, desconsiderando, por isso, suas próprias idéias como explicações igualmente válidas e coerentes, as quais elas ainda procuravam manter, mesmo com as intervenções dos professores e as reproduções do experimento com alteração dos dados.

Outra atividade, quinta atividade, realizada no segundo semestre foi a leitura do texto $A$ atuação de um investigador e as etapas do Método Científico, 
adaptado de Hennig (1986), e a resolução de um questionário sobre o texto. Com esta atividade, pretendíamos introduzir nas aulas os elementos de uma investigação. Nos encontros anteriores, havíamos feito a leitura de um projeto de pesquisa de uma aluna de outra turma do Clube de Ciências, identificando cada uma das partes e relacionando-as com perguntas como Para que a pesquisa vai ser realizada? Por que a pesquisa vai ser realizada? Como a pesquisa vai ser realizada? O uso do texto tinha por objetivo verificar se os alunos haviam aprendido a identificar elementos de um projeto de pesquisa, relacionando-as com o relato da execução de uma investigação científica.

Após a resolução do questionário, realizouse a discussão do texto sobre elementos importantes em um projeto de investigação. A discussão abordou elementos de um projeto de investigação que diferencia a produção do conhecimento científico em relação a outras formas de conhecimento. Além disso, também se colocou em questão a crença na validade do método que a doutrina positivista tornou quase um "fanatismo". Para os alunos, talvez o que considerássemos mais relevante fosse conhecer os elementos de uma pesquisa para que, a partir dela, eles pudessem desenvolver seus próprios projetos de iniciação científica.

Trouxemos como elemento de análise dessa atividade as respostas dos estudantes ao questionário. A maioria delas consistiu em transcrever trechos do texto que para eles serviu de resposta às questões. Estas transcrições, no entanto, demonstraram muitas incompreensões sobre as etapas da investigação, como uma das respostas à pergunta Para que Lazzaro desenvolveu este estudo?:

Os morcegos, sendo constatado através de consulta bibliográfica, são mamíferos dotados de asas e de hábitos noturnos. Convivem em cavernas escuras e sótãos (17 anos, $2^{\circ}$ ano, ensino médio).

Mesmo após a discussão posterior à resolução dos questionários, os estudantes permaneceram sem compreender as etapas de um projeto de pesquisa, o que percebemos mais tarde quando os orientamos a escreverem seus projetos para concorrerem a bolsas de iniciação científica oferecidas por um órgão estadual.

Naquele momento, pareceu adequado trabalhar com os alunos os elementos da investigação científica de maneira inicialmente teórica para, posteriormente, incentivar a prática.
Isso não se mostrou produtivo naquela situação, podendo ter sido diferente (ou não), caso tivessem incentivado inicialmente a prática para depois buscar a compreensão teórica. Na perspectiva de educar pela pesquisa (MORAES, 2002; DEMO, 2003), teoria e prática não são campos distintos, estando intimamente atreladas e articuladas na produção de conhecimento. Se o grupo de professores-estagiários tivesse esta compreensão naquele momento, possivelmente teria procurado outros caminhos para o desenvolvimento da atividade.

No último dia de atividades no Clube de Ciências, em 2005, no qual se realizou a Feira de Ciências interna, aplicamos o questionário de sondagem final, com o intuito de avaliar as atividades desenvolvidas e obter informações a respeito das ideias dos alunos sobre ciência. Os alunos que responderam ao questionário consideraram o ensino no CCIUFPA mais interessante e mais aprofundado que na escola, bem como destacaram a realização de projetos de iniciação científica como importantes para seu aprendizado. Entretanto, quando questionados sobre ter havido mudança em suas opiniões sobre a ciência, as respostas não foram tão claras.

Para os professores, o trabalho desenvolvido refletiu perspectivas diferentes:

Fazer uma aula em que o tópico abordado abranja todas essas áreas não é uma coisa trivial; então, no início eu achei difícil, mas depois fui me acostumando e fui desenvolvendo meu potencial e eu acho que consegui fazer boas aulas, orientar bons trabalhos e eu acho que também ajudei meus colegas no que foi preciso nos termos da matemática em relação a cada área, respectivamente (DANILO).

Danilo acredita que conseguiu romper com a visão fechada que trouxe do curso de matemática, na qual enfatizou o desprezo pela educação. Sua primeira experiência no Clube de Ciências, como o único novato da equipe, foi difícil para ele, mas diz ter desenvolvido seu potencial, feito boas aulas e orientado bons trabalhos.

A gente aprendeu muito aqui [no CCIUFPA] que o professor tem que fazer pesquisa em sala de aula, então antes de entrar no Clube de Ciências eu pensava que o professor era só chegar e dar o conteúdo (...) para o aluno. Hoje em dia eu já sei que não é bem assim, que o aluno (...) tem o conhecimento dele, que a gente tem que trabalhar esse conhecimento do aluno também e trabalhar com pesquisa, pesquisa educacional, pesquisa em sala de 
aula, professor pesquisador (RODRIGO).

Rodrigo acredita que a maior contribuição do CCIUFPA à sua formação foi aprender o papel do professor como pesquisador, que Demo (2003) enfatiza. Trabalhar os conhecimentos dos alunos também foi um aprendizado adquirido com as atividades.

As atividades tiveram significados diferentes para alunos e professores. Aos alunos, o aprendizado no CCIUFPA foi mais aprofundado e mais amplo em relação à escola, permitiu contato com a estrutura acadêmica de pesquisa e trouxe melhorias na realização de trabalhos escolares. Para os professores, o CCIUFPA se tornou um espaço de prática docente que modificou muitas de suas visões sobre educação, ciência e pesquisa.

Um ponto que queremos destacar aqui em relação a essa diferença de significados das atividades desenvolvidas para alunos e professores diz respeito às idéias sobre atividade científica. Alguns professores reconheceram a mudança de idéia a partir do trabalho desenvolvido na turma Ensino Médio B, que visava a romper com as idéias cientificistas dos alunos. No entanto, não foram detectadas mudanças de concepção nas repostas dos alunos na sondagem final, percebendo-se mesmo uma manutenção do ideário positivista, como em uma das respostas à pergunta referente à mudança de opinião sobre Ciência com as atividades desenvolvidas:

(...) antes não tinha tanta curiosidade sobre ela [a Química], mas a partir do momento que entrei no laboratório me apaixonei ( 16 anos, $2^{\circ}$ ano, ensino médio).

A "paixão" da aluna pela Química ocorreu com sua entrada no laboratório, e não ao percebê-la em seu cotidiano, por exemplo. Isso mostra que, apesar do discurso dos professores revelar uma preocupação em desmistificar a Ciência para os alunos por mais que os professores pudessem manter idéias mistificadas sobre ela, na fala da aluna não se percebe esta mudança de visão.

\section{O PENSAR E O FAZER DOCENTE NO CLUBE DE CIÊNCIAS}

As imprevisibilidades do processo de ensino/aprendizagem nos mostraram o quanto pensar e fazer não estão dissociados. Boa parte das reflexões que apresentamos neste trabalho são resultantes da reconstrução feita de um processo vivido, que me permitiu refletir sobre a prática pedagógica de um grupo de professores estagiários do CCIUFPA.

Assim, em resposta à questão inicial do trabalho, que elementos envolveram o pensar e o fazer dos professores-estagiários que compuseram a turma? Podemos dizer que:

Entendemos a importância dos conhecimentos prévios de alunos e professores em relação à atividade científica para a construção consciente e democrática de uma visão crítica e realista da ciência para ambos os lados. $\mathrm{Na}$ turma, percebemos que esta construção foi perceptível apenas para alguns dos professores, enquanto que os alunos e os outros professores não manifestaram indícios de mudança de concepção.

Percebemos que o envolvimento da turma com as atividades é um fator de grande importância para seu aprendizado. Nas atividades em que os alunos se envolveram menos, notamos maior incompreensão deles dos assuntos abordados.

Aprendemos que, mesmo que uma aula seja considerada simples, do ponto de vista de não apresentar algo tão novo, pode trazer resultados bastante positivos, como foi o experimento para o levantamento de hipóteses. A partir dele, foi possível ver o apego das alunas às suas concepções alternativas, apesar das tentativas dos professores de as confrontarem com explicações científicas. Para o objetivo da aula em si, pode ter sido um fracasso, pois os alunos demonstraram por suas falas que não mudaram suas idéias. Porém, para uma reflexão docente, foi uma atividade importante.

Compreendemos que teoria e prática se vinculam e se articulam mutuamente, sendo que uma não pode ser priorizada em detrimento da outra, como fizemos na atividade sobre as etapas da investigação científica.

Com nossa prática, com o nosso fazer, aprendemos que não éramos os únicos a ter ideias. Os alunos também tinham as suas, com o mesmo valor que as nossas. Algumas vezes, nossas ideias não nos permitiram enxergar as ideias dos alunos, assim como as ideias deles não os permitiram enxergar nossas ideias. Esta dificuldade de consenso, como algumas atividades demonstram com clareza, não nos permitiu incentivar a adoção de uma ideia mais crítica sobre a Ciência. Cremos que não há por que se procurar culpados ou inocentes por esse objetivo não 
ter sido alcançado. Há que se pensar na importância do erro para a prática docente, como Popper pensou nela para o desenvolvimento científico, e na possibilidade que temos de ter clareza disso, nesse momento. Se pensamos, fazemos e não compreendemos o que fizemos, como podemos mudar nossa maneira de pensar? Como podemos mudar nossa maneira de fazer?

O espaço experimental no Clube de Ciências da UFPA nos permitiu aprender um outro modo de perceber e vivenciar a profissão de ser professor. Ensina-nos a ser professores-pesquisadores, autores de nossas feituras, lembrando Paulo Freire. Esperamos que este trabalho sirva para incentivar outros colegas, futuros professores de Ciências, a experimentar alternativas de ensinar, aprender e refletir.

\section{REFERENCIAS}

BIANCONI, M. L. e CARUSO, F. Educação nãoformal. Ciência e Cultura. São Paulo, v. 57, n.4, 2005, p. 20.

BIEMBENGUT, M. S. e HEIN, N. Modelagem Matemática no Ensino. São Paulo: Contexto, 2003.

CALOR, A. R. e SANTOS, C. M. D. Filosofia e ensino de ciências: uma convergência necessária. Ciência Hoje. São Paulo, v. 35, n. 210, 2005.

CUNHA, M. I. Conta-me agora! As narrativas como alternativas pedagógicas na pesquisa e no ensino. Revista da Faculdade de Educação da USP. São Paulo, v. 23, n. 1-2, 1997.

DEMO, P. Pesquisa: princípio científico e educativo. 10. ed. São Paulo: Cortez, 2003.

GIL PÉREZ, D.; MONTORO, I. F.; ALÍS, J. C.; CACHAPUZ, A.; PRAIA, J. Para uma imagem não deformada do trabalho científico. Ciência $e$ Educação. São Paulo, v. 7, n. 2, 2001, p. 125-153.

GONÇALVES, T. V. O. Ensino de Ciências e Matemática e formação docente: marcas da diferença. Tese de Doutorado. Faculdade de Educação da Universidade Estadual de Campinas., 2000.
Porto Alegre: Mercado Aberto, 1986.

KOSMINSKY, L. e GIORDAN, M. Visões de Ciências e sobre cientista entre estudantes do Ensino Médio. Química Nova na Escola. Belo Horizonte, n. 15, 2002, p. 11-18.

MALDANER, O. A. Professor-pesquisador: uma nova compreensão do trabalho docente. Espaço da Escola. Ijuí, ano 4, n.31, 1999, p. 5-14.

MORAES, R. Educar pela pesquisa: exercício de aprender a aprender. In: MORAES, R. e LIMA, V. M. R. (orgs.). Pesquisa em Sala de aula: tendências para a educação em novos tempos. Porto Alegre: EDIPUCRS, 2002.

SILVEIRA, F.L. A Filosofia da Ciência de Karl Popper e suas implicações no Ensino da Ciência. In: MOREIRA, M.A. e AXT, R. (orgs.). Tópicos em Ensino de Ciências. Porto Alegre: Sagra, 1991.

A Filosofia da Ciência e o ensino de Ciências. Em aberto. Brasília, ano 11, n. 55, 1992, p. 36-41.

VIEIRA, V; BIANCONI, M. L. e DIAS, M. Espaços não-formais de ensino e o currículo de Ciências. Ciência e Cultura. São Paulo, v. 57, n.4, 2005, p. 21 23.

ZYLBERSZTAJN, A. Revoluções científicas e ciência normal na sala de aula. In: MOREIRA, M.A. e AXT, R. (orgs.). Tópicos em Ensino de Ciências. Porto Alegre: Sagra, 1991.

HENNIG, G. J. Metodologia do ensino de Ciências. 